\title{
Electrocautery technique for proximal tibial epiphysiodesis in Labrador retriever puppies: experimental study
}

\author{
[Técnica de eletrocauterização para epifisiodese proximal da tíbia em cães filhotes da raça \\ Labrador Retriever: estudo experimental]

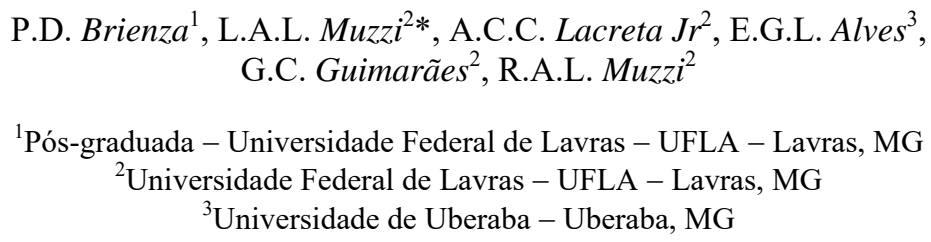

\begin{abstract}
There are few studies about the treatment options for cranial cruciate ligament rupture in growing dogs, especially with epiphysiodesis techniques. The aim of this study was to evaluate the electrocautery technique for proximal tibial epiphysiodesis in Labrador retriever puppies. The novel electrocautery technique was compared with the screw technique regarding the efficacy for tibial plateau leveling in growing dogs. Six healthy Labrador retriever puppies were divided into two groups. The screw technique was used in one group and the electrocautery technique was used in the other group. Both proximal tibial epiphysiodesis techniques for tibial plateau leveling were effective in achieving reduced tibial plateau angle and did not cause significant joint changes. The screw technique was more invasive and caused slightly greater morbidity than the electrocautery technique. The electrocautery technique seems to be a good alternative for proximal tibial epiphysiodesis in young dogs.
\end{abstract}

Keywords: cranial cruciate ligament, tibial plateau, epiphysiodesis, stifle joint, physis

\section{RESUMO}

São descritos poucos estudos sobre as opções de tratamento para a ruptura do ligamento cruzado cranial em cães na fase de crescimento, especialmente em relação às técnicas de epifisiodese. O objetivo deste estudo foi avaliar a técnica de eletrocauterização para epifisiodese proximal da tíbia em cães filhotes da raça Labrador Retriever. A nova técnica de eletrocauterização foi comparada com a do parafuso em relação à eficácia para nivelamento do platô tibial em cães na fase de crescimento. Seis filhotes saudáveis da raça Labrador foram selecionados e divididos aleatoriamente em dois grupos. A técnica do parafuso foi usada em um grupo, enquanto no outro foi usada a da eletrocauterização. Ambas as técnicas de epifisiodese proximal da tíbia para nivelamento do platô tibial foram eficazes na redução do ângulo do platô tibial e não causaram alterações articulares importantes. A técnica do parafuso foi considerada mais invasiva e causou morbidade um pouco mais acentuada do que a da eletrocauterização. Assim, a técnica da eletrocauterização parece ser uma boa alternativa para a epifisiodese proximal da tíbia em cães jovens.

Palavras-chave: ligamento cruzado cranial, platô tibial, epifisiodese, articulação do joelho, placa fisária

\section{INTRODUCTION}

Cranial cruciate ligament (CCL) is the main structure for stifle joint stability in dogs and is the primary restraint against cranial drawer motion of the tibia. It also prevents joint

Recebido em 11 de abril de 2016

Aceito em 13 de junho de 2016

*Autor para correspondência (corresponding author)

E-mail: lalmuzzi@dmv.ufla.br hyperextension, excessive internal rotation of the tibia and varus or valgus motion (Slocum and Slocum, 1993). One of the most common joint disorders in dogs is a CCL rupture (Kergosien et al., 2004; Shahar and Milgram, 2006; Duerr et al., 2008) which leads to hind limb lameness and degenerative joint disease (DJD) (Robinson et al., 2006; Bergh et al., 2008; Boudrieau, 2009). 
The rupture of the ligament may occasionally affect dogs in the growth phase. Large breed dogs usually suffer more from CCL ruptures, and Labradors have especially high risk for the disease (Vezzoni et al., 2008; McBrien et al., 2011). The causes of CCL rupture are multifactorial, especially for the degenerative process of the ligament itself and other predisposing factors, like overweight and upright stance. More recently, it was believed that this disease may occur due to the tibial plateau angle (Osmond et al., 2006; Kim et al., 2008). Radiographic exams aid in the evaluation of DJD following rupture, but they are essential for measuring the tibial plateau angle and other angles and measurements of the proximal tibia for surgical planning (Cadmus et al., 2014; Collins et al., 2014; Arruda et al., 2015). A radiographic study showed that dogs with CCL rupture have a greater angle of the tibial plateau than dogs without the disorder (Osmond et al., 2006). The natural angle of the canine tibial plateau can vary from $18^{\circ}$ to $24^{\circ}$ (Kim et al., 2008).

Whereas the tibial plateau angle is considered a predisposing factor for CCL rupture, surgical techniques have emerged that aim to alter the biomechanics of the stifle joint. These techniques do not restore the function of the ligament but provide functional joint stability during weightbearing activities (Talaat et al., 2006; Boyd et al., 2007; Christopher et al., 2013). The tibial plateau leveling osteotomies attempt to reduce the tibial plateau angle by correcting it to a new angle of approximately $5^{\circ}$ (Fettig et al., 2003; Duerr et al., 2008). By changing the slope of the tibial plateau, the cranial tibial thrust can be controlled (Kim et al., 2008). The proximal tibial epiphysiodesis by screw technique has been successfully used for tibial plateau leveling as a treatment for CCL rupture in young growing dogs (Vezzoni et al., 2008). The pattern of the proximal tibial physis was documented and can be used in the surgical planning for proximal tibial epiphysiodesis in juvenile dogs with CCL rupture (McBrien et al., 2011; Mesquita et al., 2016).

This experimental study aimed to evaluate the electrocautery technique for proximal tibial epiphysiodesis in healthy Labrador retriever puppies. The novel electrocautery technique was compared with the screw technique. The proposed hypothesis was that the electrocautery technique would be effective in leveling the tibial plateau and would provide a tibial plateau angle that neutralizes the cranial tibial thrust in the adult dog.

\section{MATERIAL AND METHODS}

This study was approved by the Ethics Committee on Animal Use from the Institution (CEUA-UFLA 003/10). The techniques proposed for tibial plateau epiphysiodesis were performed on Labrador retriever dogs, which is one of the most predisposed breeds to CCL rupture. Six healthy five-month-old puppies were selected and randomly divided into two groups of three animals each for the surgical procedures. In one group, a screw technique was used, and in the other group, a novel electrocautery technique was applied.

Immediately prior to surgery, the dogs underwent orthopaedic clinical examination and both stifle joints of each animal were evaluated with conventional radiographic exams in craniocaudal and mediolateral projections. Mediolateral radiographs were performed with the stifle joint at an angle of approximately $135^{\circ}$, which is the limb support angle of the joint. In the mediolateral radiographs, measurements were taken of the tibial plateau angle and patellar ligament angle in relation to the tibial plateau (Collins et al., 2014, Arruda et al., 2015). The craniocaudal radiographs were taken to confirm the health of the joint during the preoperative period and to evaluate possible joint changes in the postoperative period. After the preoperative measurements and surgical preparation, the right hind limb was subjected to the epiphysiodesis procedure for tibial plateau leveling while the left hind limb remained intact for evaluation as a control joint in all dogs.

Three animals underwent proximal tibial epiphysiodesis using the screw technique. An approach via craniolateral surface of the stifle joint was used. A lateral parapatellar incision was used to perform the arthrotomy and expose the proximocranial surface of the tibial plateau. First, a guide pin was introduced to identify the central region of the cranial tibial plateau, at the level of the sulcus of the long digital extensor tendon. An intraoperative radiograph was performed to confirm correct placement of the 
guide pin. Subsequently, a hole was made at the site with a pneumatic drill and orthopedic drill bit. A 3.5-mm diameter and 24-mm long cortical screw was inserted parallel to the tibial axis, settling on the proximocranial surface of the tibial plateau. The joint capsule and the tissue layers were sutured routinely.

The other three animals underwent proximal tibial epiphysiodesis using an electrocautery technique. The surgical approach was similar to the previous technique, but the arthrotomy was not necessary. The cranial portion of the tibial plateau physis was identified through partial divulsion of the cranial tibial muscle insertion on the lateral surface and the muscle fascia on the medial surface of the proximal tibia. Elevation of the periosteum was necessary for both craniolateral and craniomedial portion to correctly identify the physis of the tibial plateau. The electrocautery was performed on the cranial third of the of the tibial plateau physis, both the medial and lateral surfaces. An electrocautery device was used at 75 watts for 15 seconds at each point cauterized and saline washing was performed between each cauterization. The electrocautery rod was inserted at four consecutive points on each side of the cranial portion of the physis. Thereafter, the tissue layers were routinely sutured.

The dogs were followed until the end of the skeletal growth period at 12 months of age. The animals were evaluated using orthopedic clinical and radiographic examinations, and operated and contralateral control joints were always analyzed. The orthopedic evaluation was performed biweekly using a scoring classification system, in which parameters such as lameness and limb support, presence of articular crepitus, pain sensitivity, drawer test, and tibial compression tests were evaluated. Lameness was graded as sound, mild, moderate, severe lameness or nonweight bearing. The joint range of motion was measured using goniometry, and presence of meniscal click, joint effusion and localized edema were also evaluated.

After the surgical intervention, the dogs were initially assessed biweekly using conventional radiographic exams. After stabilization of the tibial plateau angle, the radiographic exams were then performed monthly until the dogs were 12 months of age. In radiographs the positioning of the screw, the integrity of the joint structures, and the possibility of developing DJD were evaluated. The tibial plateau angle and the patellar ligament angles in relation to the tibial plateau were also measured.

Descriptive statistical analyses were performed with orthopedic and radiographic exam data. The Wilcoxon Mann Whitney test was used to compare the qualitative and ordinal variables (lameness and pain sensitivity) between the independent samples for the different techniques. A paired Student's t-test was used to compare the efficiency of tibial leveling before and after the techniques were performed. To compare the effects of the techniques on other quantitative and numeric variables in the control and treated limbs, the $\mathrm{F}$ test was used to determine the homogeneity of variances, and Student's t-test was then applied for homogeneous or heterogeneous variances, as required for the analysis in question. For all tests, $\mathrm{p}$ values below 0.05 were always considered significant.

\section{RESULTS}

During the postoperative period, clinical and orthopedic exams indicated that the animals subjected to the screw technique showed slightly more evident joint signs. The animals submitted to the screw technique presented with mild to moderate lameness at 15 days postoperative and mild level at 30 days, and at 45 days one dog still presented with mild lameness. In the electrocautery group at 15 days post-surgery, two animals presented with mild lameness and one with moderate level, and only one dog presented with mild lameness at 30 days. After 45 days and 60 days of postoperative none of the animals of the electrocautery group and screw group presented with lameness, respectively. The clinical signs of lameness were significantly higher at 15 and 30 days postoperative in the screw technique group and significantly higher only at 15 days postoperative in the electrocautery group.

Regarding pain sensitivity on clinical examination after the surgical procedures, only one animal belonging to the screw technique group showed evidence of pain at 15 days postoperative, specifically during the extension movement of the operated limb. There were no significant differences between the groups in 
relation to pain sensitivity after performing the two surgical techniques. The animals that received the screw technique presented with moderate to intense edema on the surgical site 15 days postoperatively, and mild edema persisted at the 30 days of postoperative evaluation. In contrast, only one animal that received the electrocautery technique presented with mild localized edema at 15 days, and none of the animals subjected to this technique presented with edema at 30 days of postoperative. Regardless of the surgical technique used, the dogs showed no changes in the postoperative period for the drawer test, tibial compression test, presence of meniscal click, and presence of crepitus during joint movements. There was no valgus or varus deformity evaluated clinically and radiographically.

The thigh circumference measurements of the control limbs and operated limbs at 15 days postoperative indicated that the operated limbs appeared to have less muscle mass gain (screw) and/or relative muscle loss (electrocautery) compared to the control limbs. Despite these apparent differences at this stage, there were no statistically significant differences in thigh circumference measurements between the control limbs and operated limbs by the two techniques. There were no significant differences in thigh circumference between the control limbs and operated limbs throughout the postoperative follow-up, and the operated limbs tended to be equal for both surgical techniques.

There was no significant difference in mean flexion angle between the control limbs and the operated limbs for the two surgical techniques. However, the statistical analysis revealed that the mean extension angle between the control limbs and the operated limbs were significantly different at 15, 30, 45 and 60 days post-surgery. Comparisons of the mean extension angle between the surgical groups showed that dogs submitted to the screw technique had lower values for this feature from the early postoperative period until 45 days. The animals submitted to the electrocautery technique did not show evident changes in hind limb extension over the same period.

The measurements of the tibial plateau angle of control limbs and treated limbs revealed that in both epiphysiodesis techniques there was a prominent reduction in the angle of the tibial plateau. In the control limbs, there were no statistically significant differences in the tibial plateau angle before and after the procedure. The statistical analysis showed a significant reduction in the tibial plateau angle in the operated limbs in both epiphysiodesis techniques. Comparatively with the preoperative data, the significant difference in the tibial plateau angle measurement was early observed at 15 days of postoperative in the electrocautery technique group, whereas the difference was significant only 30 days after surgery with the screw technique (Table 1).

In the tibial plateau angle measurements, the electrocautery technique achieved an approximate angle of $5^{\circ}$ at 60 days postoperatively, whereas the screw technique achieved this same approximate angle at 90 days. Based on the means for the two surgical procedures, the tibial plateau angle continued to decrease until it stabilized just below the angle of $5^{\circ}$, with mean values of $3.67^{\circ}\left(6^{\circ} / 5^{\circ} / 0^{\circ}\right)$ and $4^{\circ}$ $\left(6^{\circ} / 6^{\circ} / 0^{\circ}\right)$ for the electrocautery and screw techniques, respectively. The stabilization of the tibial plateau angle in operated limbs occurred earlier in the dogs of the electrocautery technique, which occurred at 90 days and 120 days postoperatively for the electrocautery and screw technique groups, respectively (Fig. 1). In contrast, the mean tibial plateau angle values of the control limbs for the dogs submitted to both surgical techniques indicated that there was initially a slight increase in the angle, followed by a trend for the stabilization of the mean tibial plateau angle around $25^{\circ}$ for the screw group and $22^{\circ}$ for the electrocautery group (Table 1 ).

The measurements of the patellar ligament angle in relation to the tibial plateau in the operated hind limbs showed that in both epiphysiodesis techniques there was a reduction in this angle, which reached approximate values of $90^{\circ}$ over the course of the postoperative exams. At the end of the evaluation period, mean angles of $86.67^{\circ}$ and $90.33^{\circ}$ were observed in the operated joints that were subjected to the screw and electrocautery techniques, respectively. In contrast, the mean patellar ligament angle in the control limbs during the evaluation period was approximately $100^{\circ}$, with a mean of $98.33^{\circ}$ in both groups at the end of the study (Table 2). 
Table 1. Values (mean \pm standard deviation) of the tibial plateau angle $\left(^{\circ}\right)$ evaluated in dogs subject to proximal tibial epiphysiodesis using the screw technique or the electrocautery technique

\begin{tabular}{lcccc}
\hline \multirow{2}{*}{$\begin{array}{l}\text { Days of } \\
\text { evaluation }\end{array}$} & \multicolumn{2}{c}{ Screw } & \multicolumn{2}{c}{ Electrocautery } \\
\cline { 2 - 5 } $4 \mathrm{~m}$ & Treatment & Control & Treatment & Control \\
$5 \mathrm{~m}$ pre & $23.00 \pm 1.00$ & $23.33 \pm 1.53$ & $21.67 \pm 1.53$ & $21.33 \pm 0.58$ \\
15 days post & $24.00 \pm 1.73$ & $24.33 \pm 1.15$ & $22.33 \pm 0.58$ & $21.67 \pm 0.58$ \\
30 days post & $20.00 \pm 3.00$ & $24.33 \pm 1.15$ & $17.00 \pm 1.00^{*}$ & $22.00 \pm 1.00$ \\
45 days post & $16.00 \pm 1.00^{*}$ & $24.33 \pm 1.15$ & $12.67 \pm 1.53^{*}$ & $22.00 \pm 1.00$ \\
60 days post & $10.67 \pm 1.53^{*}$ & $25.00 \pm 0.00$ & $8.33 \pm 1.53^{*}$ & $22.00 \pm 1.00$ \\
75 days post & $8.00 \pm 2.00^{*}$ & $25.33 \pm 0.58$ & $4.67 \pm 1.53^{*}$ & $22.67 \pm 0.58$ \\
90 days post & $7.67 \pm 2.52^{*}$ & $25.33 \pm 0.58$ & $4.67 \pm 1.53^{*}$ & $22.67 \pm 0.58$ \\
105 days post & $4.67 \pm 4.04^{*}$ & $25.33 \pm 0.58$ & $3.67 \pm 3.21^{*}$ & $22.33 \pm 0.58$ \\
120 days post & $4.33 \pm 3.79^{*}$ & $25.33 \pm 0.58$ & $3.67 \pm 3.21^{*}$ & $22.33 \pm 0.58$ \\
150 days post & $4.00 \pm 3.46^{*}$ & $25.33 \pm 0.58$ & $3.67 \pm 3.21^{*}$ & $22.33 \pm 0.58$ \\
180 days post & $4.00 \pm 3.46^{*}$ & $25.33 \pm 0.58$ & $3.67 \pm 3.21^{*}$ & $22.33 \pm 0.58$ \\
210 days post & $4.00 \pm 3.46^{*}$ & $25.33 \pm 0.58$ & $3.67 \pm 3.21^{*}$ & $22.33 \pm 0.58$ \\
240 days post & $4.00 \pm 3.46^{*}$ & $25.33 \pm 0.58$ & $3.67 \pm 3.21^{*}$ & $22.33 \pm 0.58$ \\
\hline
\end{tabular}

$\left({ }^{\circ}\right)=$ degrees; $4 \mathrm{~m}=4$ months of age; $5 \mathrm{~m}=5$ months of age; pre $=$ preoperative; post $=$ postoperative. $*$ Values that differ from preoperative values by the paired t-test $(\mathrm{p}<0.05)$.

Table 2. Values (mean \pm standard deviation) of the patellar ligament angle $\left({ }^{\circ}\right)$ evaluated in dogs subject to proximal tibial epiphysiodesis using the screw technique or the electrocautery technique

\begin{tabular}{lcccc} 
Days of & \multicolumn{2}{c}{ Screw } & \multicolumn{2}{c}{ Electrocautery } \\
\cline { 2 - 5 } evaluation & Treatment & Control & Treatment & Control \\
\hline $4 \mathrm{~m}$ & $113.33 \pm 4.16$ & $113.33 \pm 4.73$ & $114.33 \pm 5.86$ & $114.00 \pm 3.61$ \\
$5 \mathrm{~m}$ pre & $107.67 \pm 2.52$ & $110.33 \pm 2.89$ & $111.67 \pm 3.51$ & $108.67 \pm 8.14$ \\
15 days post & $110.67 \pm 5.13$ & $109.33 \pm 5.13$ & $107.33 \pm 2.52$ & $107.67 \pm 2.52$ \\
30 days post & $104.67 \pm 7.57$ & $105.33 \pm 2.52$ & $100.67 \pm 1.15$ & $105.33 \pm 1.53$ \\
45 days post & $104.00 \pm 10.58$ & $107.00 \pm 2.65$ & $103.67 \pm 5.13$ & $109.00 \pm 3.61$ \\
60 days post & $95.67 \pm 2.52$ & $107.00 \pm 1.00$ & $94.00 \pm 2.65$ & $104.67 \pm 9.24$ \\
75 days post & $89.67 \pm 3.51$ & $103.00 \pm 4.58$ & $96.67 \pm 6.43$ & $106.00 \pm 2.00$ \\
90 days post & $89.00 \pm 2.65$ & $105.00 \pm 3.00$ & $93.67 \pm 3.79$ & $104.00 \pm 3.61$ \\
105 days post & $89.33 \pm 4.16$ & $104.67 \pm 4.51$ & $98.00 \pm 2.00$ & $105.67 \pm 2.31$ \\
120 days post & $89.33 \pm 2.08$ & $103.33 \pm 1.53$ & $93.67 \pm 5.86$ & $103.33 \pm 2.89$ \\
150 days post & $88.67 \pm 4.16$ & $102.67 \pm 2.52$ & $95.00 \pm 4.58$ & $104.00 \pm 3.00$ \\
180 days post & $90.33 \pm 2.52$ & $103.00 \pm 4.36$ & $94.67 \pm 7.64$ & $104.33 \pm 4.62$ \\
210 days post & $86.33 \pm 4.93$ & $102.00 \pm 6.00$ & $91.67 \pm 3.06$ & $100.33 \pm 4.51$ \\
240 days post & $86.67 \pm 4.73$ & $98.33 \pm 4.16$ & $90.33 \pm 1.53$ & $98.33 \pm 4.51$ \\
\hline
\end{tabular}

$\left(^{\circ}\right)=$ degrees; $4 \mathrm{~m}=4$ months of age; $5 \mathrm{~m}=5$ months of age; pre = preoperative; post $=$ postoperative.

\section{DISCUSSION}

The CCL injuries can occur at any age, including immature dogs. There are few studies about the treatment of the CCL rupture in growing dogs, especially with the proximal tibial epiphysiodesis technique (Vezzoni et al., 2008). Tibial osteotomies have shown favorable results as corrective surgical techniques for this condition, but they can be inappropriate for young puppies and they are very invasive. This study evaluated the efficacy of two epiphysiodesis techniques for CCL rupture, based on the tibial plateau leveling from the growth modulation of the physis. The procedures performed resulted in a prominent reduction of the tibial plateau angle in Labrador puppies. Relying on the theory that the tibial plateau angle of dogs is one of the predisposing factors for CCL rupture (Bergh et al., 2008), both proximal tibial epiphysiodesis techniques proved to be efficient procedures and can be an option for the CCL rupture treatment in puppies. In some young dogs predisposed to progressive CCL strains because of the excessive tibial plateau angle (Talaat et al., 2006), a preventive epiphysiodesis technique could be an alternative procedure to avoid the cruciate disease. 

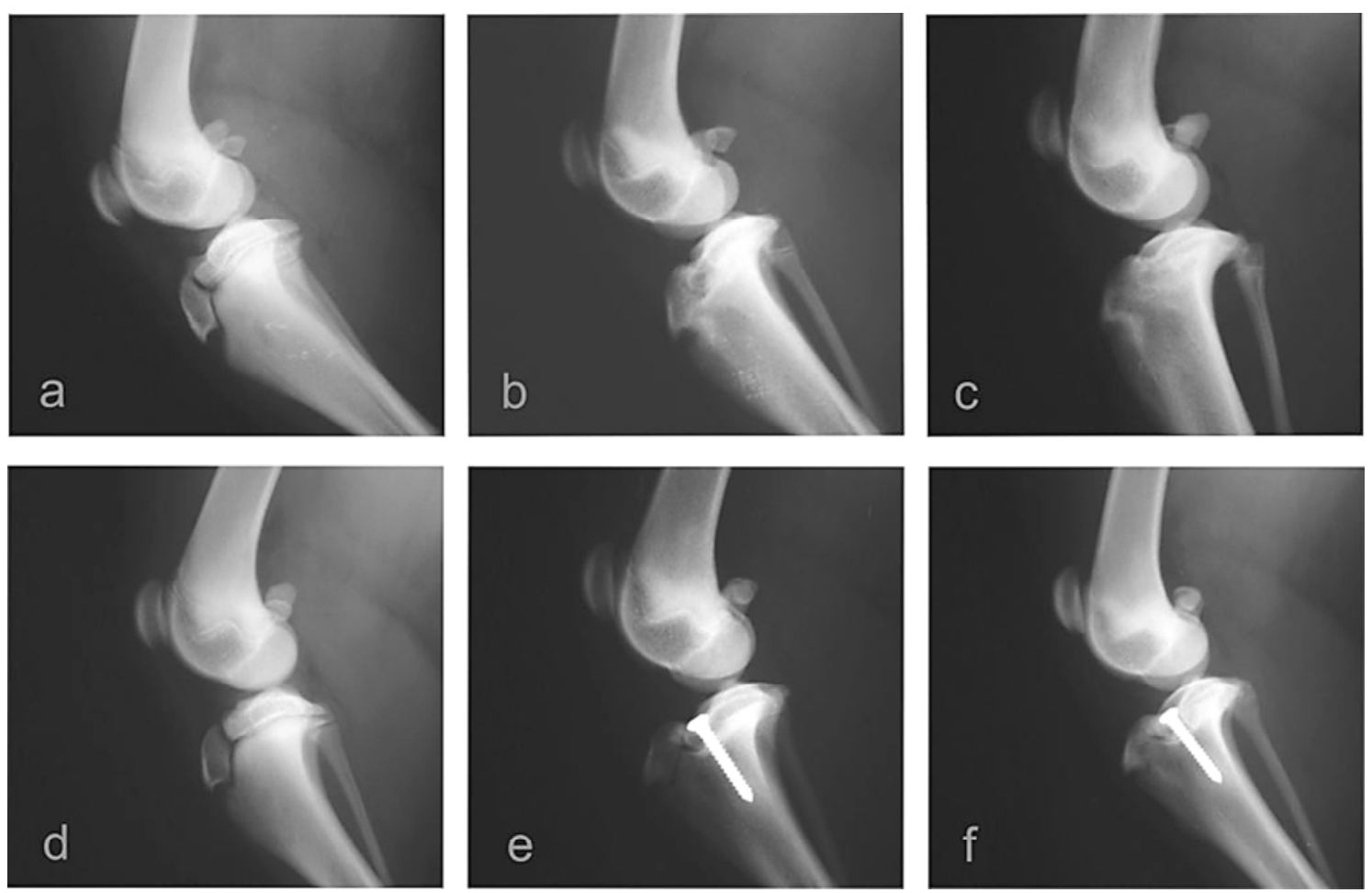

Figure 1. Radiographic images of the operated stifle joints of dogs subject to proximal tibial epiphysiodesis using the screw technique or the electrocautery technique. ( $a, b$ and $c)$ : preoperative and postoperative at 90 and 120 days following the electrocautery technique. (d, e and f): preoperative and postoperative at 90 and 120 days following the screw technique. Note: postoperative exams at 90 days (b) and 120 days (f) correspond to the dates on which the tibial plateau angles stabilized after the application of the electrocautery and screw techniques, respectively.

The clinical evaluations performed in the postoperative period showed that all animals experienced relatively rapid recovery of the operated limb. However, the dogs that underwent the screw technique presented with more local edema and joint effusion and were more susceptible to clinical pain and lameness in the first month after surgery than the animals of the electrocautery technique. These findings occurred possibly due to a higher degree of invasion and joint aggression with the screw technique. The parapatellar arthrotomy for the diagnosis of CCL disease may be associated with the occurrence of patellar desmopathy, and this change might be lower if arthrotomy were not performed (Kühn et al., 2011). Therefore, in this study, the most pronounced occurrence of joint effusion and edema at the operation site for the screw technique was likely related to the greater degree of invasiveness of the arthrotomy. It is possible that the morbidity presented in the screw technique could be avoided with the use of fluoroscopic surgery. Even in the electrocautery technique, the degree of surgical invasiveness could be reduced with the use of percutaneous epiphysiodesis by fluoroscopy.

In this study, the surgical techniques were performed on five-month-old Labrador dogs that still had significant potential for bone growth and good possibility for tibial plateau leveling after the procedure. The epiphysiodesis technique using a screw fixation was studied for the treatment of CCL rupture in 5- to 8-month-old dogs (Vezzoni et al., 2008) and a pilot study was performed to evaluate epiphysiodesis techniques in a growing mongrel dog (Mesquita et al., 2016). In the current study, the two of the three animals that received the screw technique had the tibial plateau angle reduced to $6^{\circ}$, and the two of the three animals that received the electrocautery technique had the angle reduced to $5^{\circ}$ and $6^{\circ}$. The values of these angles are considered optimal angulation values for the tibial plateau to prevent cranial tibial translation during weight bearing (Reif et al., 2002; Kim et 
al., 2008). However, one animal from each surgical technique had the tibial plateau angle reduced to $0^{\circ}$. Although an angle of $0^{\circ}$ is not advised, as this may mechanically compromise the integrity of the caudal cruciate ligament (Shahar and Milgram, 2006), the clinical and radiographic evaluations in short term follow up did not indicate any structural or functional disorder in these limbs. In one study, Labrador dogs that were treated with TPLO for CCL rupture were evaluated, and the operated limbs regained their full functionality when the tibial plateau angle remained between $0^{\circ}$ and $14^{\circ}$ after surgery (Robinson et al., 2006).

For the screw technique, when the optimal tibial plateau angle was achieved and the physis was still open, the removal of the screw may be indicated to avoid excessive reduction of the angle (Vezzoni et al., 2008). In contrast to the possibility of controlling the degree of tibial plateau slope using the screw technique, in the electrocautery technique it is not possible to interrupt the process of reducing the plateau angle until the end of the growth phase. The limitation of uncontrolled tibial plateau leveling using the electrocautery can be regarded as a potential cause for the excessive leveling. Therefore, it is important to know the ideal age for each specific breed for performing the surgical technique for tibial plateau leveling. In this study the surgical procedures were performed in Labrador dogs at 5 months of age and according to the findings probably 5.5 months would be better, because individual variation in growth dynamics should be considered (McBrien et al., 2011; Mesquita et al., 2016). The values of the tibial plateau angles of the control limbs remained within the limits considered normal for dogs, which naturally vary from $18^{\circ}$ to $24^{\circ}$ (Kim et al., 2008). In both surgical techniques studied, no clinical or radiographic changes were observed in the control limbs, demonstrating that the animals did not functionally overload their contralateral stifle joints in a relatively short follow-up period.

An appropriate reduction in the patellar ligament angles in relation to the tibial plateau was observed in the operated limbs for both techniques in this study, evidencing that the patellar ligament angles approached to the recommended value of $90^{\circ}$ (Sathya et al., 2014). According to biomechanical theories in dogs, the tibiofemoral joint forces are directed parallel to the patellar ligament during limb support (Schwandt et al., 2006; Drygas et al., 2010), making the tibial cranial thrust dependent on the angle formed between the patellar ligament and the tibial plateau (Cadmus et al., 2014). Thus, if the patellar ligament is oriented perpendicular to the tibial plateau during limb support, there will be no tangential force resulting from the total force on the stifle joint, neutralizing the tibial cranial thrust (Dennler et al., 2006). In one study, dogs with a partial CCL rupture exhibited higher values for the angles formed between the patellar ligament and the tibial plateau compared to animals with healthy joints (Schwandt et al., 2006).

In this study, favorable results were demonstrated regarding the efficacy of proximal tibial epiphysiodesis techniques. However, some limitations can be highlighted. One limitation is the small number of animals used, as only three animals were evaluated for each surgical technique. Another aspect is the follow-up period of the dogs after the procedure, which lasted only until the animals were 12 months of age. Ideally the dogs should be followed over their lifetime to effectively draw conclusions about the efficacy and safety of the surgical procedures. Thus, future studies should be conducted to examine the long-term beneficial effects of electrocautery technique in puppies with clinical rupture of the CCL.

\section{CONCLUSION}

In conclusion, the study demonstrates that the proximal tibial epiphysiodesis with the screw or electrocautery technique seem to be effective for tibial plateau leveling in growing Labrador dogs. Both epiphysiodesis techniques provide expressive reduction in tibial plateau angles without causing major joint changes. The techniques allow rapid patient recovery after the procedure. Finally, the present study suggests that electrocautery causes less morbidity than the screw technique and the electrocautery technique seems to be a good alternative for proximal tibial epiphysiodesis.

\section{ACKNOWLEDGEMENTS}

The authors acknowledge the financial support by FAPEMIG and CAPES. 


\section{REFERENCES}

ARRUDA, A.F.D.P.; MUZZI, L.A.L.; MUZZI, R.A.L. et al. Comparison of the proximal tibial angles between labrador retrievers and other dog breeds with and without cranial cruciate ligament rupture. Arq. Bras. Med. Vet. Zootec., v.67,p.1254-1262, 2015.

BERGH, M.S.; RAJALA-SCHULTZ, P.; JOHNSON, K.A. Risk factors for tibial tuberosity fracture after tibial plateau leveling osteotomy in dogs. Vet. Surg., v.37, p.374-382, 2008.

BOUDRIEAU, R.J. Tibial plateau leveling osteotomy or tibial tuberosity advancement? Vet. Surg., v.38, p.1-22, 2009.

BOYD，D.J.; MILLER，C.W.; ETUE，S.M.; MONTEITH, G. Radiographic and functional evaluation of dogs at least 1 year after tibial plateau leveling osteotomy. Can. Vet. J., v.48, p.392-396, 2007.

CADMUS, J.; PALMER, R.H.; DUNCAN, C. The effect of preoperative planning method on recommended tibial tuberosity advancement cage size. Vet. Surg., v.43, p.995-1000, 2014.

CHRISTOPHER, S.A.; BEETEM, J.; COOK, J.L. Comparison of long-term outcomes associated with three surgical techniques for treatment of cranial cruciate ligament disease in dogs. Vet. Surg., v.42, p.329-334, 2013.

COLLINS, J.E.; DEGNER, D.A.; HAUPTMAN, J.G.; DECAMP, C.E. Benefits of preof pre $\square$ and intraoperative planning for tibial plateau leveling osteotomy. Vet. Surg., v.43, p.142-149, 2014.

DENNLER, R.; KIPFER, N.M.; TEPIC, S. et al. Inclination of the patellar ligament in relation to flexion angle in stifle joints of dogs without degenerative joint disease. Am. J. Vet. Res., v.67, p.1849-1854, 2006.

DRYGAS, K.A.; POZZI, A.; GORING, R.L. et al. Effect of tibial plateau leveling osteotomy on patellar tendon angle: a radiographic cadaveric study. Vet. Surg., v.39, p.418-424, 2010.

DUERR, F.M.; DUNCAN, C.G.; SAVICKY, R.S. et al. Comparison of surgical treatment options for cranial cruciate ligament disease in large-breed dogs with excessive tibial plateau angle. Vet. Surg., v.37, p.49-62, 2008.
FETTIG, A.A.; RAND, W.M.; SATO, A.F. et al. Observer variability of tibial plateau slope measurement in 40 dogs with cranial cruciate ligament-deficient stifle joints. Vet. Surg., v.32, p.471-478, 2003.

KERGOSIEN, D.H.; BARNHART, M.D.; KESS, C.E. et al. Radiographic and clinical changes of the tibial tuberosity after tibial plateau leveling osteotomy. Vet. Surg., v.33, p.468-474, 2004.

KIM, S.E.; POZZI, A.; KOWALESKI, M.P.; LEWIS, D.D. Tibial osteotomies for cranial cruciate ligament insufficiency in dogs. Vet. Surg., v.37, p.111-125, 2008.

KÜHN, K.; OHLERTH, S.; MAKARA, M. et al. Radiographic and ultrasonographic evaluation of the patellar ligament following tibial tuberosity advancement. Vet. Radiol. Ultrasound, v.52, p.466-471, 2011.

MCBRIEN, C.S.; VEZZONI, A.; CONZEMIUS, M.G. Growth dynamics of the canine proximal tibial physis. Vet. Surg., v.40, p.389-394, 2011.

MESQUITA, L.R.; MUZZI, L.A.L.; GIANNICO, A.T. et al. Proximal tibial epiphysiodesis in a growing dog. Acta Sci. Vet., v.44, Suppl.1, p.113, 2016.

OSMOND, C.S.; MARCELLIN-LITTLE, D.J.; HARRYSSON, O.L.; KIDD, L.B. Morphometric assessment of the proximal portion of the tibia in dogs with and without cranial cruciate ligament rupture. Vet. Radiol. Ultrasound, v.47, p.136141, 2006.

REIF, U.; HULSE, D.A.; HAUPTMAN, J.G. Effect of tibial plateau leveling on stability of the canine cranial cruciate-deficient stifle joint: an in vitro study. Vet. Surg., v.31, p.147-154, 2002.

ROBINSON, D.A.; MASON, D.R.; EVANS, R.; CONZEMIUS, M.G. The effect of tibial plateau angle on ground reaction forces 4-17 months after tibial plateau leveling osteotomy in labrador retrievers. Vet. Surg., v.35, p.294-299, 2006.

SATHYA, S.; GILBERT, P.; SHARMA, A.; HENDRICK, S. Effect of tibial plateau levelling osteotomy on patellar tendon angle: a prospective clinical study. Vet. Comp. Orthop. Traumatol., v.27, p.346-350, 2014. 
SCHWANDT, C.S.; BOHORQUEZ-VANELLI, A.; TEPIC, S. et al. Angle between the patelar ligament and tibial plateau in dogs with partial rupture of the cranial cruciate ligament. Am. J. Vet. Res., v.67, p.1855-1860, 2006.

SHAHAR, R.; MILGRAM, J. Biomechanics of tibial plateau leveling of the canine cruciatedeficient stifle joint: a theoretical model. Vet. Surg., v.35, p.144-149, 2006.

SLOCUM, B.; SLOCUM, T.D. Tibial plateau leveling osteotomy for repair of cranial cruciate ligament rupture in the canine. Vet. Clin. N. Am. Small Anim. Pract., v.23, p.777-795, 1993.
TALAAT, M.B.; KOWALESKI, M.P.; BOUDRIEAU, R.J. Combination tibial plateau leveling osteotomy and cranial closing wedge osteotomy of the tibia for the treatment of cranial cruciate ligament-deficient stifles with excessive tibial plateau angle. Vet. Surg., v.35, p.729-739, 2006.

VEZZONI, A.; BOHORQUEZ-VANELLI, A.; MODENATO, M. et al. Proximal tibial epiphysiodesis to reduce tibial plateau slope in young dogs with cranial cruciate ligament deficient stifle. Vet. Comp. Orthop. Traumatol., v.21, p.343-348, 2008. 